\title{
A EXOTIZAÇÃo NO PERÍODO COLONIAL E Pós-colonial: o Caso de Portugal dos PeQuenitos
}

\author{
Antunes Rafael Kaiumba Pinto \\ Departamento de Língua e Culturas, Centro de Línguas, Literaturas e Culturas, Universidade de Aveiro, Portugal \\ Maria Manuel Baptista \\ Departamento de Língua e Culturas, Centro de Línguas, Literaturas e Culturas, Universidade de Aveiro, Portugal
}

\begin{abstract}
RESUMO
Este artigo aborda o tema das representações portuguesas coloniais nos espaços turísticos e tem o seu principal foco de incidência na forma como o colonizado é representado pelo colonizador. Durante cinco séculos, Portugal manteve um extenso império, que foi sendo objeto de representações ligadas ao exótico e a seres em estado de inferioridade civilizacional. Tal ponto de vista, de um olhar superior e hegemónico, continua representado no Portugal dos Pequenitos, visitado por milhares de crianças e turistas adultos de todo o mundo, alimentando a indústria turística, ao mesmo tempo que naturaliza as relações de poder colonial. Por conseguinte, no presente estudo, questionam-se as representações das ex-colónias portuguesas, através da análise museológico-turística do conteúdo da exposição de 1940 e replicada no Portugal dos Pequenitos, em Coimbra, e conclui-se tratar de um discurso turístico impregnado pelo olhar exótico do colonizador sobre as suas ex-colónias, o que corresponde a uma representação, ainda, luso-tropical de um Portugal imperial.
\end{abstract}

PALAVRAS-ChAVE

exotização; Portugal dos Pequeninos; império

\section{EXOTIZATION IN THE COLONIAL AND POST-COLONIAL Period: The CASe of Portugal dos Pequenitos}

\begin{abstract}
This article addresses the theme of Portuguese colonial representations in tourist spaces and mainly focuses on how the colonized are represented by the colonizer. For five centuries, Portugal maintained an extensive empire, which was the subject of representations of exoticism and of people in a state of civilizational inferiority. Such a superior and hegemonic point of view remains represented in the theme park Portugal dos Pequenitos, visited by thousands of tourists, children, and adults, from all over the world, feeding the tourist industry, while naturalizing colonial power relations. Therefore, in the present study, we examine the representations of Portugal, through a museological-tourist analysis of the discourse of the Portuguese World Exhibition of 1940, replicated in the theme park Portugal dos Pequenitos, in Coimbra. We conclude that it is a tourist discourse impregnated by the exoticizing look of the colonizer at the former colonies, which still corresponds to a lusotropicalist representation of an imperial Portugal.
\end{abstract}




\section{A edificação do Portugal dos Pequenitos}

Foi no intervalo de 1936-1939 que se construiu o parque, que é, ainda hoje, conhecido como o Portugal dos Pequenitos, idealizado por Bissaya Barreto e projetado pelo arquiteto Cassiano Branco. O projeto, que tinha como objetivo principal representar o Império português, foi inaugurado no ano de 1940. Nele estão representadas casas regionais, típicas dos países incluídos no "mundo português", espaços ilustrativos e característicos de Portugal, de Norte a Sul, com os seus monumentos, praças e ruas, reproduzindo a história da metrópole, os seus heróis e os seus feitos mais importantes. Também não falta a representação cultural das colónias (a sua flora, fauna e etnografia), incluindo, ainda, os arquipélagos.

Em pleno Estado Novo, o projeto constituía uma demonstração de força e era acompanhado por práticas e discursos formulados de diversas formas e maneiras. $O$ Império era apresentado ao mundo como grande, mas o complexo todo a que se chamava o "mundo português" não passava, na realidade, de uma utopia. No espaço onde se localizam as cinco colónias de África, cada uma delas com o seu pavilhão e onde se descrevem as riquezas de cada um deles, designadamente riqueza cultural, económica e dos seus povos, juntam-se, ainda, dois outros espaços: um que representa as colónias portuguesas na Índia, e outro que representa um pavilhão - Portugal-Brasil, onde estes dois países aparecem descritos como pátrias irmãs.

Martins (2016) é de opinião de que o espaço do Portugal dos Pequenitos é um campo de demostração de poder e força, bem como de instrumentos que caraterizavam o regime que foi sempre protegido com as ações da religião católica:

esta imanência do poder, aquilo a que Gilles Deleuze chama o "mapa" ou a "cartografia", atravessa, por exemplo, todo o espaço do Portugal dos Pequenitos, esse brinquedo político que é também um modelo reduzido de poder, construído em Coimbra nos anos 30. É aí visível o encaixe espacial de uma teia de controlos hierarquizados. A igreja da aldeia e a igreja da missão colonial são no Portugal dos Pequenitos aquilo que a moral cristã é na arte da vigilância eugénica: uma "câmara escura" na grande ciência óptica que a disciplina salazarista constitui. (Martins, 2016, p. 92)

A conceção ideológica e social, idealizada no período da administração do território além-mar, tinha uma vertente pedagógica que procurava narrar as práticas dos colonizadores:

o Parque dos Pequenitos não deve ser considerado um museu de miniatura arquitetónica de Portugal. Esse julgamento limitaria, em demasia, a inteligência e a cultura veiculada por esta obra, por não se terem apercebido 
da feição pedagógica desta obra, inspirada nos métodos preconizados e difundidos pelos maiores pedagogos. (Matos, 2006, p. 23)

A construção do Portugal dos Pequenitos procurava, ainda, responder a quem lançasse dúvidas sobre a grandeza e o carácter imperial de Portugal, enquanto procurava reforçar a noção de portugalidade e projetar a ideia da sua influência benéfica no mundo.

Não podendo ser aceite como um museu que tende a narrar de uma forma imparcial, ou a mais objetiva possível, uma determinada realidade, uma vez que aquilo que faz é naturalizar as ações coloniais, é importante olhar para aquela realidade sob o ponto de vista das teorias pós-coloniais e perceber que estamos perante um ato colonial, de subalternização e que representa a glória mitológica de um império que nunca saiu do imaginário, mas, que o procura, pedagogicamente, construir:

o "Portugal dos Pequenitos" (PP) é uma representação de Portugal elaborada para as crianças. Tem, por isso, um objectivo claramente pedagógico. Ao contrário de outras exposições da época, este espaço não foi destruído e, por essa razão, ainda pode ser visitado. O PP é aqui analisado no sentido de se perceber quais e como foram construídas as imagens coloniais dadas a ver às crianças. (Matos, 2006, p. 228)

Sem adotar esse olhar crítico, no ano de 2000, o Governo português atribuiu ao Portugal dos Pequenitos a medalha de mérito turístico, não considerando o facto de aquele local contribuir para difundir um mito da superioridade ideológica, que reforça a manutenção de determinados elementos do passado e que conta uma história unilateral, do ponto de vista do colonizador.

No entanto, Portugal dos Pequenitos carrega consigo a ideia do amanhã. A Pátria é projetada para o futuro como encargo a ser definido pelos, então, habitantes do local. Na verdade, é através delas que esta ideia de Pátria se perpetuará e que se terá, enfim, o ideal modelo do "ser português". (Paulo, 1990, p. 405)

\section{TURISMO, CULTURA E IDEOLOGIA}

As origens do turismo são muito remotas, e vários autores debruçaram-se já sobre esta problemática. As formas mais antigas remontam à Antiguidade Clássica e remetem aos gregos, aos egípcios e aos romanos, uma vez que a troca de produtos de uma região para outra, bem como as viagens por motivos diversos, originavam contactos entre os povos. Mais recentemente, foi a Revolução Industrial do século XVIII, que deu o grande impulso ao turismo.

O lugar tem vindo a suscitar mais interesse por parte de estudiosos, investigadores e académicos, enquanto tem atraído maior interesse em novos turistas que apresentam uma motivação crescente em conhecer mais sobre esta temática (Costa, 2014, p. 570). 
Portugal dos Pequenitos coloca Portugal numa posição de hiperidentidade pelo facto de, num pequeno espaço, narrar a história da colonização para com as suas ex-colónias, e, para as crianças que visitam o local, é-lhes passada a informação da ação generosa e benevolente que a colonização portuguesa teria tido para com os outros povos. A realidade presente e visível é a de um roteiro turístico sobre a colonização, que se desenvolve entre Lisboa e as colónias, uma história que narra a diversidade cultural dos povos.

O turismo cultural que é apresentado no Portugal dos Pequenitos constitui-se como o meio de proporcionar uma nova abordagem à superioridade de Portugal disfarçada na lusofonia, que procura compreender os interesses de todos os povos de forma igualitária. Com o objetivo de recontar a história desde Portugal marítimo até chegar aos povos colonizados, mostrando, assim, o génio colonizador. (Silva \& Vasconcelos, 2014, p. 159)

Para a temática em causa, interessa, contudo, fazer uma análise da relação entre turismo e cultura, uma vez que estes dois agentes dificilmente estão separados. Na realidade, o turismo pode ser feito de várias formas. Por exemplo, como refere Dores (2015), há um período em que se associavam as viagens e o mundo cultural, ou seja, viajar

consistia numa forma de turismo praticada pela aristocracia, em especial a inglesa, que tem início no século XVIII e em que a viagem pela Europa incluía visitas aos grandes locais históricos artísticos e naturais, afirmando, assim, que o património cultural é um dos mais antigos e importantes elementos gerador de turismo. (Dores, 2015, p. 61)

Por esta citação, vemos como o turismo e a cultura se articulam em torno da noção de património e da vontade de conhecer o património cultural dos povos.

O termo património vem do romano patrimonium e está associado aos bens materiais de uma família, tendo o termo evoluído para um conceito coletivo relativo a um conjunto de bens comuns (Audrerie, 1997).

No caso do património cultural, este traduz a preocupação do presente e o desejo de que este presente se ligue ao reconhecimento de uma herança do passado, assumindo-o, deste modo, como um fator fundamental de identidade.

No que diz respeito ao Portugal dos Pequenitos, e tendo em conta a observação feita no local, na ocasião em que elaboramos este estudo, podemos dizer que ele tem mais um pendor turístico do que cultural, ou mesmo, histórico. O turismo passou a dominar aquele espaço onde o exótico tem uma expressão muito notória e marca o espaço e a experiência turística que proporciona. A articulação entre turismo e cultura é quase inexistente, porque se dão mais explicações sobre o que é o espaço do que sobre o significado da existência das representações nos pavilhões, o que vem acentuar mais o poder hegemónico que, supostamente, Portugal tenha exercido nas suas colónias. Tal como realça Baptista, 
neste contexto, a questão do Outro ou é mera divisão alimentada pela busca do exótico e do inesperado, ou não é mais do que a tentativa de recuperar, agora por outros meios, mais enviesados e distorcidos, a eterna busca do sujeito por si próprio, numa lógica que nada tem de inovador ou surpreendente, mas que pode ser toda encontrada já na fenomenologia do espírito. (Baptista, 2017, p. 19)

$\mathrm{Na}$ verdade, a aparente diversidade interna deste espaço disfarça mal a representação hegemónica do colonizador, que mais se escreve a si próprio do que ao outro. Com aquela representação, Portugal projeta-se como sujeito de uma ação civilizadora, relegando para um plano secundário espaços que, parecendo estarem representados, são, afinal, invisibilizados: o que é aí representado é o pitoresco, o exótico que estimula o olhar do turista acrítico e predador da diferença irredutível.

No entanto, devemos reforçar a ideia de que a cultura não pode ser refém do turismo. Tal como a afirma Dores (2015), o património cultural é um dos mais antigos e importantes elementos geradores do turismo e não devemos ofuscar e representar, de modo caricato, a cultura em função de objetivos turísticos.

Com efeito, o que está presente no jardim e que foi antecedido pela exposição mundial a que nos referiremos adiante, será, ainda, ressignificado pelo luso-tropicalismo (Castelo, 1999), na década de 6o, tendo passado incólume pela Revolução de 1974.

Ao chegar aos nossos dias, como uma das atrações turísticas mais visitadas da região centro do país, mostra bem o modo como o luso-tropicalismo se encontra naturalizado e a mentalidade imperial ainda persiste e nunca foi, totalmente, erradicada a autorrepresentação dos portugueses. "O Império português é essencialmente de Portugal, enquanto os demais povos são o Outro desse império" (Silva \& Vasconcelos, 2014, p. 160).

Tal como refere Baptista (2017), "o Império português em África nunca existiu até ao século XIX, pois, não conseguiu mais do que ocupações territorialmente muito circunscritas à costa africana, destinadas essencialmente a manter uma atividade comercial com os nativos" (p. 63).

Falando de um mundo português que, para alguns autores, nunca existiu, divulgava-se uma falsa ideia de coabitação pacífica entre Portugal e as colónias. Com efeito, a ideia de um ultramar como um lugar de encontro de culturas, fundamenta-se, teoricamente, no luso-tropicalismo (Baptista, 2017).

O contacto de culturas manifesta um desejo utópico de retratar a história e as relações entre diferentes comunidades (...) como sendo uma relação sem poder, sem conflito. (....) Estou a pensar, por exemplo, na retórica que preside às comemorações dos descobrimentos portugueses ou à criação da CPLP [Comunidade dos Países de Língua Portuguesa], ou à própria ideia de lusofonia. (Baptista, 2017, p. 17)

A ideia que se tem sobre o Portugal dos Pequenitos é mais a de um espaço turístico do que a de um local histórico, com a afirmação categórica de um poder hegemónico 
em que a cultura aparece atrelada ao turismo, contribuindo numa representação ideologicamente colonial do Império português.

\section{Representação hegemónica de Portugal através do discurso turístico}

Desde que Portugal se lançou na famosa missão civilizadora, com a vontade e paixão de conquista do mundo, foi demonstrando a ideia de que tudo o que fosse terra e onde houvesse vida deveria ficar sob o seu domínio, nas palavras de Luís de Camões, inscritas em lugar de destaque no Portugal dos Pequenitos, "se mais mundo houver, lá chegara".

Partindo desta máxima de cariz imperialista e hegemónico, no sentido em que Gramsci (2007) refere que "os colonizadores servem como modelo e como medida que se aplicará aos povos colonizados, aplicação vista não como um ato de dominação, mas como um ato de salvação" (p. 34), foi este espírito hegemónico que alimentou a cartilha ideológica do Portugal colonial.

Note-se, também, que esta posição paternalista assume várias intensidades consoante a própria cronologia do processo de descolonização. Por exemplo, sendo o Brasil a primeira ex-colónia a tornar-se independente, passa a ser reconhecida como pátria-irmã, num gesto que tem um contexto e um significado histórico especiais.

\section{EXPOSIÇÃO DE 1940}

A ideia de celebrar a dupla efeméride da fundação do Estado de Portugal e da restauração da sua nacionalidade (1140 e 1640) esteve na origem da "Exposição do Mundo Português", ideia que foi lançada em 1929 pelo embaixador Alberto de Oliveira e que seria assumida em março de 1938 por Salazar, através de uma nota oficiosa da Presidência do Conselho. A exposição surgiu na sequência da participação portuguesa nas grandes exposições internacionais de Paris (1937), Nova lorque e São Francisco (1939) (Matos, 2006).

Tal como aconteceu na expansão, no tráfico de escravos, Portugal teve de arranjar uma oportunidade para mais uma vez se mostrar ao mundo pelos seus feitos, visto que a sua ação sobre as demais potências estava a enfraquecer. Assim, Martins (2016) afirma que a exposição realizada era para reconstruir historial de um Portugal imperial e colonizador:

a exposição constitui uma gigantesca reconstituição histórica em material efémero (estuque, madeira, estruturas plásticas), tendo sido aí reinventadas as tradições de oito séculos da vida nacional. Tratou-se de proclamar ao mundo a grandeza de um "país uno, multirracial e pluricontinental". E para a concretização desse objetivo havia que mobilizar os símbolos e as narrativas adequados, dado o facto de a história nunca falar por si própria. $\mathrm{Na}$ Exposição do Mundo Português reinventou-se, pois, uma história para falar pela identidade nacional. (Martins, 2016, p. 21) 
A exposição foi realizada entre a margem direita do Rio Tejo e o Mosteiro dos Jerónimos, ocupou uma área de cerca de 560 mil metros quadrados, e teve dois grandes pavilhões longitudinais perpendiculares: o Pavilhão de Honra de Lisboa e, do outro lado, o Pavilhão dos Portugueses no Mundo (Ribeiro, Alessandretti, Leandro, Martins \& Moraes, 2017).

Foi com base neste último pavilhão que foi idealizado o Portugal dos Pequenitos, proposto por Bissaya Barreto. Foi construído em Coimbra e, na esteira do enaltecimento da grande obra de Salazar, também ele procura ser a expressão gloriosa e civilizadora do Império português. Mas, tal como sugere Baptista (2017), não será antes um regresso e um retorno do recalcado? O que verificamos é que muitas dessas representações que continuam a vigorar no imaginário cultural português, talvez não passem do regresso do recalcado, ou de um encontro falhado com a realidade (Baptista, 2017).

No caso em apreço, a representação colonial nunca deixou que os autóctones falassem por si próprios, mas fez sempre questão de os representar como povo atrasado, parado nos confins de um tempo primitivo e resgatado pela missão civilizadora do seu colonizador. Com efeito, se Portugal é enaltecido na grandeza da sua missão, "já o negro ou o indígena aparece, quando muito, como uma nota exótica na paisagem" (Baptista, 2017, p. 55).

Ora, é esta representação que organiza, estruturalmente, o Portugal dos Pequenitos, havendo que referir que uma notícia da RTP de cultura, publicada a 9 de janeiro de 2018, afirma que em 2017, o parque foi visitado por 27.300 .000 pessoas, numa escala percentual de $40 \%$ de turistas, sendo os demais público escolar. Os que mais frequentaram o espaço foram os espanhóis, franceses e brasileiros.

\section{O DISCURSO TURÍSTICO NO PERÍODO COLONIAL E NO PÓS-COLONIAL}

Para termos uma ideia do discurso colonial e pós-colonial no olhar turístico, torna-se necessário analisar as imagens que se encontram no jardim dos pequenitos, nas placas que, supostamente, deveriam ser as cartas dos pavilhões. Ficamos surpreendidos com uma placa onde se lê a frase "Portugal e Brasil pátrias irmãs", e com outra, na parte frontal do espaço, em que se descreve Portugal como metrópole. Para compreendermos a sua importância e significado na atualidade, sublinhemos que se trata, ainda, aqui de

veicular uma determinada imagem de Portugal, enquanto Império português e, sobretudo, do "outro" desse Império, o que verificamos é que muitas dessas representações continuam a vigorar no imaginário cultural português, talvez não de todo o escol intelectual português, mas certamente numa parte dele e em maior escala na memória cultural portuguesa. (Baptista, 2017, p. 57)

Nesta linha de pensamento, Dores (2015) considera que só fantasmaticamente as colónias africanas eram, ou foram, o outro Portugal. Só o Brasil foi um Portugal-Outro, ou assim inconscientemente descrito (Caldeira, 2015, p. 76). Também o discurso do 
Portugal dos Pequenitos joga com as identidades, de forma a legitimar relações de poder e a naturalizar a superioridade do colonizador sobre o colonizado, no processo de anexação de territórios sob a ideia de império. Sobre este processo de manipulação e construção de um imaginário imperial, Baptista (2017) assinala o seguinte:

umas das mais impressionantes tarefas de manipulação da identidade e da memória próprias (e imediatamente da identidade e da memória do Outro) foi o processo de colonização que os europeus levaram a cabo em diversas partes do mundo e de forma mais intensa, nos finais dos séculos XIX e XX em África. (Baptista, 2017, p. 61)

As descrições que, realmente, mostram a presença portuguesa em África e não só, com as colónias a serem representadas em pequena dimensão, relativamente ao império, reforçam os mecanismos de poder relativamente aos povos que estiveram sob a sua dependência. Tal como descreve Castelo, o luso-tropicalismo ajudou a sedimentar este imaginário imperial:

essa unidade existe e o português é o seu elemento fundador e aglutinador. As características do português, já analisadas em Casa-Grande e Senzala ausência de preconceito racial, apetência pela miscigenação, cristianismo fraternal - são o que confere a coerência interna ao mundo por ele criado entre os povos. (Castelo, 1999, p. 35)

No entanto, na atualidade, os Estudos Pós-coloniais desafiam os antropólogos, historiadores, museólogos e turismólogos a repensarem as suas representações, a exercerem uma crítica constante sobre elas.

A crítica pós-colonial realizou a introdução de uma crítica radical aos padrões de conhecimento e de identidades sociais que não era autorizada pelo colonialismo e pelo domínio ocidental. Isto não significa que o colonialismo e seus legados tenham permanecido inquestionados até hoje; basta pensar, por exemplo, nos nacionalismos ou no marxismo; significa, sim, que ambos funcionavam graças a narrativas-mestras que colocavam a Europa no centro.

A crítica pós-colonial procurará, então, desfazer o eurocentrismo, mantendo, porém, a consciência de que a pós-colonialidade não se desenvolve num olhar panóptico em relação à história; a pós-colonialidade existe como um depois - depois de ter sido trabalhada pelo colonialismo.

O espaço ocupado pelo Portugal dos Pequenitos mostra que a enunciação de discursos de dominação não se localiza nem dentro, nem fora, da história da dominação portuguesa, mas, antes, numa relação profunda com ela.

No contexto atual, vários são os olhares que foram construídos sobre o espaço em debate. Martins (2016) descreve dois tipos de cenários:

falamos do tão celebrado Portugal dos Pequenitos, que não é apenas uma ilustração do organismo nacional. É também um engenho político, um 
modelo reduzido de poder: obsessão de Salazar, ditador minucioso da maquineta doméstica, das oficinas familiares e corporativas bem disciplinadas, dos prolongados exercícios da memória, do olhar e do desejo. (Martins, 2016, p. 165)

Depois de ter visitado o Portugal dos Pequenitos, onde supostamente está representado o mundo português, vemos que o outro continua a ser representado sem história e sem legenda, e pouco ou nada se sabe dele, ideia que vem desde os tempos imperiais e que para o turista representa apenas uma curiosidade exótica, acriticamente absorvida.

Pelo facto de ser visitada por crianças, segundo Martins (2016), não se traduz num local turístico mas sim, num espaço de reinventar os atos que vivem na memória coletiva dos povos, elevando, assim, a hiperidentidade dos portugueses, e subalternizando, cada vez mais, os povos no passado, "sonhar-se-á, neste sentido, com as visitas de crianças que ao Portugal dos Pequenitos vêm aprender as tendências virtuosas que regeneram a nação doente: lição viva ou museu da ordem regeneradora" (Martins, 2016, p. 93).

\section{CONSIDERAÇÕES FINAIS}

Definitivamente, tal como Baptista (2017) já concluíra, sucede que a imagem que o ex-colonizador tem procurado mostrar remete a uma ação imaginária de um suposto império que, no domínio do real, não existiu. O Portugal dos Pequenitos é, de facto, um espaço criado para replicar uma prática cruel levada a cabo por parte de quem um dia pensou que era superior ao outro e que procura, ainda, veicular essa ideia para as novas gerações, através da valorização do exótico.

Posto isto, privilegiar o olhar exótico no turismo cultural corresponde a uma ocultação grave da verdade dos povos representados no Portugal dos Pequenitos. Valorizando a componente da atratividade para o público e o turismo de lazer, nesse jardim é explorado o lado pitoresco, bizarro e estranho de povos que aparecem como primitivos e que são vistos como atrasados e inferiores.

É, todavia, importante não deixar que estas representações, encenadas para fins turísticos, permaneçam por descodificar e é importante perceber de onde veem os discursos e as representações que estão por detrás destas projeções imaginárias. Tal como é, mais uma vez, referido por Baptista:

o turismo em África resumia-se à caça grossa, no contexto de um turismo que hoje designaríamos, cinegético e de aventura, ao passeio pelas grandes obras da colonização europeia (fazendas e obras públicas). Em qualquer dos casos, atrativos africanos para o turismo eram a natureza e o elemento humano branco, realizador da transformação lenta e paulatina de África. Já o negro ou o indígena aparece, quando muito, como uma nota e exótica na paisagem. (Baptista, 2017, p. 55) 
Hoje, o Portugal dos Pequenitos é um espaço que, embora tenha sofrido algumas alterações no tocante a remodelações de pormenor, continua a contribuir para uma inferiorização dos povos ex-colonizados. Encontra-se aberto ao público e continua a fazer prevalecer a narrativa colonial, contando a história, sem qualquer crítica ou olhar póscolonial. É assim um museu da atualidade que narra e procura manter o colonialismo.

Num olhar mais técnico sobre a arquitetura do espaço é evidente que existe uma ação de subalternização: num mesmo espaço dois tipos de construções, as pertencentes às ex-colónias, em forma de barracas, e as pertencentes à metrópole, o que é representado pela arquitetura da época. Se no passado os mesmos territórios eram suas propriedades, por que razão tinham os dois tipos de arquitetura? Porém, Martins (2016) ajuda-nos a responder a esta questão da seguinte forma:

mantenhamos ainda como referência o paradigma arquitectural do Portugal dos Pequenitos, cujo funcionamento táctico reenvia ao dispositivo eugénico da prática discursiva salazarista. Portugal dos Pequenitos é a figura arquitectural de um aparelho que funciona segundo o modo de dois sonhos políticos que se combinam na dupla composição de construções circulares (as aldeias e as colónias) e de construções rectangulares (os monumentos, os castelos e as praças fortificadas). (Martins, 2016, p. 93)

O Portugal dos Pequenitos é um grande parque para a diversão das crianças que visitam o espaço e veem relatada como grandiosa uma triste realidade: é a colonização tratada como diversão, passando como divertida a narrativa de valores coloniais e imperiais que se tornaram anacrónicos e inumanos.

\section{REFERÊNCIAS}

Audrerie, D. (1997). La notion et la protection du patrimoine (1..$^{\text {a }}$ ed.). Presses Universitaires de France.

Baptista, M. M. (2017). O 'génio colonial português'. O papel dos media na criação de um Mundo Português. Coimbra: Grácio Editor.

Caldeira, S. C. P. (2015). Relações de poder e identidade(s) de género: a sociedade "matriacal" de ílhavo na década de 1950. Tese de Doutoramento, Universidade de Aveiro, Aveiro, Portugal. Retirado de https:// repositorio.ipbeja.pt/bitstream/20.500.12207/4604/1/Sandra Caldeira.pdf

Castelo, C. (1999). O modo português de estar no mundo. O luso-tropicalismo e a ideologia portuguesa (19331961). Porto: Edições Afrontamento.

Costa, D. S. (2014). Belém - o mundo lusófono a dois passos: proposto de roteiro turístico-cultural em Belém (Lisboa). In M. M. Baptista \& S. V. Maia (Eds.), Colonialismos, pós-colonialismos e lusofonias - Atas Do IV Congresso Internacional Em Estudos Culturais (pp. 570-578). Coimbra: Grácio Editora.

Dores, H. G. (2015). A missão da República. Politica, religião e o império colonial português (1910-1926). Lisboa: Edições 70.

Gramsci, A. (2007). Cadernos do cárcere - Vol. 4. Temas de cultura, ação católica. Americanismo e fordismo (2. ${ }^{a}$ ed.). Rio de Janeiro: Civilização Brasileira. 
Martins, M. de L. (2016). O olho de Deus no discurso salazarista (2. ${ }^{\mathrm{a}}$ Ed.). Porto: Edições Afrontamento. Retirado de http://repositorium.sdum.uminho.pt/handle/1822/49972

Matos, P. F. de. (2006). As "côres" do império: representações raciais no "império colonial português" (3. ${ }^{\text {a }}$ ed.). Lisboa: ICS. Retirado de http://hdl.handle.net/10451/22688

Paulo, H. H. de J. (1990). "Portugal dos Pequenitos": uma obra ideológico-social de um professor de Coimbra. Revista de História Das Ideias, 12, 395-413. https://doi.org/10.14195/2183-8925_12_14

Ribeiro, D. L., Alessandretti, M. R. A., Leandro, R.da S., Martins, L. T. \& Moraes, F. R. (2017). A presença na ausência: a performance e a biografia dos objetos como ativadores de memória. Midas, 8, 1-16. https:// doi.org/10.4000/midas.1286

\section{NotAS BIOGRÁFICAS}

Antunes Rafael Kaiumba Pinto é doutorando em Estudas Culturais na Universidade Aveiro, mestre em Desenvolvimento Curricular, pela Universidade Agostinho Neto em Angola e licenciado em História pela Universidade Agostinho Neto em Angola. É investigador do Centro de Línguas, Literatura e Culturas da Universidade de Aveiro. A tese de doutoramento aborda as narrativas das representações de Portugal e Angola nos manuais escolares do ensino primário no período colonial - uma perspetiva pós-colonial.

ORCID: https://orcid.org/oooo-0002-7183-1974

Email: antunespinto@ua.pt

Morada: Campus Universitário de Santiago, 3810-193 Aveiro, Portugal

Maria Manuel Baptista é Professora Catedrática da Universidade de Aveiro, com Agregação em Estudos Culturais, pela Universidade do Minho (2013). Tem uma obra diversa e extensa, publicada nacional e internacionalmente, com ênfase na área dos Estudos Culturais. É Presidente da IRENNE - Associação de Investigação, Prevenção e Combate à Violência e Exclusão. É coordenadora do GECE - grupo de Género e Performance e do NECO - Núcleo de Estudos em Cultura e Ócio da Universidade de Aveiro. É editora da coletânea "Género e Performance: Textos Essenciais". Entre os seus interesses de investigação contam-se as questões da identidade e globalização, bem como migração e pós-colonialismo.

ORCID: https://orcid.org/oooo-0002-1465-4393

Email: mbaptista@ua.pt

Morada: Campus Universitário de Santiago, 3810-193 Aveiro, Portugal

\section{Submetido: 04/05/2020 \\ Aceite: $30 / 07 / 2020$}

